\title{
Capillary Versus Arterial Plasma Catecholamines as Markers for Sympatho-Adrenal Activity in Infants
}

\author{
HOLGER BAUMGARTNER, REINHOLD RITSCH, OSWALD LUZ, JOHANNES SCHNEEBERGER, \\ AND IGNAZ HAMMERER \\ Institut für Biochemische Pharmakologie [H.B., R.R.] and Universitätsklinik für Kinderheilkunde [O.L., J.S., \\ I.H.J, Universität Innsbruck, A-6020 Innsbruck, Austria
}

\begin{abstract}
In this study, we investigated whether capillary plasma catecholamines can be used as a suitable substitute for arterial catecholamines. Analysis was done radioenzymatically. Catecholamine concentrations were not different in arterial and simultaneously collected "arterialized" (warmed foot) capillary plasma obtained by heel-prick from 18 neonatal intensive care patients as assessed by linear regression analysis (correlation coefficient: 0.966 for noradrenaline; 0.894 for adrenaline; $p<$ $0.05)$ and by a Wilcoxon test [noradrenaline: $2.13(0.61-$ 10.47) versus $2.41(1.05-10.23)$; adrenaline: $0.75(0.16-$ $1.70)$ versus $0.72(0.10-1.37) \mathrm{nmol} / \mathrm{L}$, median (range)] However, "arterialization" of capillary blood is important; when blood was obtained in nine neonates without warming their feet, capillary concentrations of noradrenaline were higher than arterial values $(p<0.03)$ and those of adrenaline were not different from arterial values. Catecholamine concentrations in arterialized capillary plasma collected in healthy full-term infants at $1 \mathrm{~h}[n=9$; noradrenaline: 6.85 (3.09-8.88) $\mathrm{nmol} / \mathrm{L}$; adrenaline: $1.34(0.86-2.85) \mathrm{nmol} / \mathrm{L}]$ and $5 \mathrm{~d}$ after birth $[n=27$; noradrenaline: $1.58(0.89-3.16)$ nmol/L; adrenaline: $0.59(0.25-1.64) \mathrm{nmol} / \mathrm{L}]$ reflect the well-known fall $(p<0.01)$ in catecholamine levels after delivery. With a highly sensitive analytical technique, catecholamine concentrations can reliably be assessed in minute samples (100-200 $\mu \mathrm{L})$ of arterialized capillary blood, even when concentrations have dropped to low "resting" basal levels. Moreover, the capillary sampling procedure is simple and safe, can easily be applied to healthy infants, and does not have the practical and ethical limitations of arterial blood sampling. (Pediatr Res 31: 579-582, 1992)
\end{abstract}

\section{Abbreviations}

CAT, catecholamine

$A$, adrenaline

NA, noradrenaline

Plasma CAT are successfully used to study the stressful perinatal adaptation of infants. Both very high levels of circulating CAT and easy access to blood (1-16) facilitate investigation at this stage. Under normal circumstances, these advantages no longer exist soon after birth when specimens have to be collected invasively from an artery or a vein $(1,2,5,6,17)$; these sampling

Received August 16, 1991; accepted January 15, 1992.

Correspondence and reprint requests: Holger Baumgartner, M.D., Institut für Biochemische Pharmakologie der Universität Innsbruck, Peter Mayrstr. 1, A-6020 Innsbruck, Austria.

Supported by Dr. Legerlotz-Stiftung. procedures can have ethical and practical limitations, particularly in healthy infants. The aim of this study was to investigate whether the use of capillary plasma CAT can be an alternative.

\section{MATERIALS AND METHODS}

Patients. Blood was obtained from 27 neonatal intensive care patients for comparison of capillary and arterial CAT concentrations and for determination of arterial blood gases. Heart rate and arterial blood pressure were monitored. All patients were in stable circulatory conditions at the time of investigation.

Group 1. For comparison of "arterialized" capillary with arterial CAT concentrations, two blood samples were taken simultaneously by heel prick from the hyperemic (warmed) foot and from an indwelling umbilical arterial catheter in 18 infants (five girls, 13 boys) between $\mathrm{d} 1$ and 14 (mean $5.5 \mathrm{~d}$ ) after birth (average gestational age, $35 \mathrm{wk}$ ). Their birth weights ranged from 1240 to $4230 \mathrm{~g}$ (mean, $2423 \mathrm{~g}$ ); five were full-term and 13 were preterm babies.

Group 2. For comparison of "nonarterialized" capillary with arterial CAT concentrations, two blood samples were taken simultaneously by heel prick from the nonhyperemic foot and from an indwelling umbilical arterial catheter in nine infants (four girls, five boys) between $\mathrm{d} 1$ and 13 (mean $3.3 \mathrm{~d}$ ) after birth (average gestational age, $35 \mathrm{wk}$ ); their birth weights ranged from 980 to $4730 \mathrm{~g}$ (mean, $2381 \mathrm{~g}$ ); three were full-term and six were preterm babies.

Healthy neonates. Arterialized capillary blood (warmed foot) was obtained by heel prick from two groups of apparently healthy, full-term infants, when capillary puncture was done for routine medical purposes. All 27 newborns had uneventful neonatal periods; birth weights were $3334 \pm 294 \mathrm{~g}$ (mean \pm SD). Two groups were studied.

Group 3. Eighteen infants (nine girls, nine boys) were studied on approximately their 5 th $\mathrm{d}$ of life.

Group 4. Nine infants (two girls, seven boys) born during the daytime by uncomplicated deliveries (five vaginally and four by cesarean section) with Apgar scores of 10 at 10 min were studied at $1 \mathrm{~h}$ after birth and approximately d 5 (4-6) after birth.

The study protocols had been approved by the ethical committee of the medical faculty and parental consent was obtained.

Blood samples. Specimens for CAT determination were collected before the routine blood samples, and care was taken to conduct arterial and capillary sampling simultaneously. Strongly hemolytic samples $(n=5)$ were rejected, but four slightly hemolytic specimens were analyzed (18). Capillary blood (100-200 $\mu \mathrm{L}$ ) was collected using 200- $\mu \mathrm{L}$ glass capillaries (Brand Inc., Wertheim, Germany) in less than 1 min. Hyperemization was done by nurses according to established ward routine, i.e. by applying a diaper warmed to approximately $42^{\circ} \mathrm{C}$ with hot tap water for about $5 \mathrm{~min}$ before sampling. Arterial blood (300-500 
$\mu \mathrm{L})$ was collected, giving consideration to catheter dead space. Blood samples were transferred immediately to polyethylene tubes (CB-1000, Li-heparinate; Sarstedt Inc., Nümbrecht, Germany), kept on ice and centrifuged within $30 \mathrm{~min}$ at $4^{\circ} \mathrm{C}$ for 5 min. Plasma was deproteinized by adding an equal volume of $0,6 \mathrm{~N}$ perchloric acid containing $0.2 \%$ EGTA and $0.02 \% \mathrm{MgCl}_{2}$. $6 \mathrm{H}_{2} \mathrm{O}(19)$. Deproteinized samples were kept at $-20^{\circ} \mathrm{C}$.

Analysis. Catecholamines in arterial, capillary, and control plasma samples were determined by a previously described (20) radioenzymatic method with the following modifications: only $25 \mu \mathrm{L}$ of deproteinized plasma were used; $5 \mu \mathrm{Ci}$ S-adenosylmethionine- $3 \mathrm{H}$ of a high radioactive concentration were added in $5 \mu \mathrm{L}$ of volume [Amersham TRK 865 (Amersham Int. plc, Buckinghamshire, UK); $1 \mathrm{mCi} / \mathrm{mL}]$.

Samples were assayed in duplicate, and CAT [NA, $29 \mathrm{fM}$; A, $27 \mathrm{fM}$; dopamine, $32 \mathrm{fM}$ (5 pg each)] were added to a third sample aliquot as internal standard [control plasma, duplicate plus two internal standards ( 5 and $10 \mathrm{pg}$ )]. Precision was about $10 \%$, variability $15 \%$, and detection limit about $3 \mathrm{fM}(>0.5 \mathrm{pg})$ per sample tube for NA and $\mathrm{A}$ as assessed with a control plasma obtained from pooled peripheral venous blood of adults (NA, $1.57 \mathrm{nmol} / \mathrm{L}$; A, $0.37 \mathrm{nmol} / \mathrm{L}$ ). Reproducibility with arterial as well as capillary samples was estimated over the concentration range of group 1 (Table 1, Fig. 1) by linear regression analysis of the respective first and second values of the duplicate determinations. The following correlation coefficients $(p<0.05)$, intecepts (nmol/L), and slopes were found: $0.98,0.05$, and 0.99 for arterial NA; $0.96,0.0$, and 1.04 for arterial $\mathrm{A} ; 0.99,-0.1$, and 1.04 for capillary NA; and $0.98,0.04$, and 0.92 for capillary A.

Statistical analysis. Linear regression analysis with $95 \%$ confidence interval for the fitted regression line, Pearson product moment coefficient, Wilcoxon's matched-pairs signed rank test, Kendall rank correlation coefficient, Mann-Whitney U-test, mean $\pm S E M$, and mean $\pm S D$ were used.

\section{RESULTS}

Group 1: Arterialized Capillary Versus Arterial Plasma CAT. $A$ and NA concentrations in arterialized capillary blood were not different from those in arterial blood as assessed by linear regression analysis (Fig. 1, Table 1) and by a Wilcoxon test (Table 1). Omission of hemolytic samples $(n=2)$ had no significant influence on these results (Table 1 , footnote). In these patients, blood pressure [mean (range)] was $69 \mathrm{~mm} \mathrm{Hg}$ (47-94) systolic and 43 $\mathrm{mm} \mathrm{Hg} \mathrm{(24-79)} \mathrm{diastolic,} \mathrm{heart} \mathrm{rate} \mathrm{was} 145$ bpm (80-170), arterial $\mathrm{pH}$ was $7.4(7.32-7.57), \mathrm{PO}_{2}$ was $68 \mathrm{~mm} \mathrm{Hg}(54-107)$ [9 $\mathrm{kPa}(7-14)$, and $\mathrm{PCO}_{2}$ was $40 \mathrm{~mm} \mathrm{Hg}$ (24-54) [5 kPa (3-7)]. There was no difference in these parameters between those patients who cried during the sampling procedure $(n=11)$ and those who did not $[n=7)$. Positive correlations were found between NA and A (arterial and capillary) versus heart rate ( $p<$ $0.03)$; A (arterial and capillary) versus postpartal age $(p<0.01)$; NA (arterial and capillary) versus $\mathrm{PCO}_{2}(p<0.03)$ and versus A (arterial and capillary; $p<0.001$ ). Negative correlations were found between NA (arterial and capillary) versus gestational age $(p<0.01)$, weight $(p<0.04)$, and $\mathrm{pH}(p<0.05)$.

Group 2: Nonarterialized Capillary Versus Arterial Plasma $C A T$. The results of a comparison between CAT in arterial and nonarterialized capillary plasma are shown in Table 1 . NA concentrations were substantially and significantly $(p<0.03)$ higher in nonarterialized capillary than in arterial blood, but $\mathrm{A}$ concentrations were not different. The patients from group 2 were in clinical conditions comparable to those of group 1 with blood pressures [mean (range)] of $67 \mathrm{~mm} \mathrm{Hg} \mathrm{(49-96)} \mathrm{systolic}$ and $45 \mathrm{~mm} \mathrm{Hg}$ (34-70) diastolic, heart rates of $148 \mathrm{bpm}(120$ 175), arterial $\mathrm{pH}$ of $7.36(7.27-7.48), \mathrm{PO}_{2}$ of $72 \mathrm{~mm} \mathrm{Hg}(62-98)$ [10 $\mathrm{kPa}(8-13)]$, and $\mathrm{PCO}_{2}$ of $40 \mathrm{~mm} \mathrm{Hg}(30-47)$ [5 kPa [4-6)].

Groups 3 and 4: Arterialized Capillary Plasma CAT in Healthy Neonates. Group 3. The capillary plasma concentrations of NA and A [median (range)] in group 3 on approximately their 5 th $\mathrm{d}$ of life, shown in Figure 2 (left panel), were $1.56 \mathrm{nmol} / \mathrm{L}(0.89$ 2.97) for NA and $0.61 \mathrm{nmol} / \mathrm{L}(0.38-1.09)$ for A. Capillary plasma catecholamines were not different between the sexes or between those babies who cried during blood sampling $(n=10)$ and those who did not ( $n=7$; no information was obtained in one case).

Group 4. As shown in Figure 2 (right panel), capillary plasma CAT levels in group 4 are much higher at $1 \mathrm{~h}$ after birth than approximately $5 \mathrm{~d}$ later $(p<0.01)$ when they are not different from those of group 3.

The values of all 27 healthy neonates at approximately d 5 were [median (range)] $1.58 \mathrm{nmol} / \mathrm{L}(0.89-3.16)$ for NA and 0.59 $\mathrm{nmol} / \mathrm{L}(0.25-1.64)$ for $\mathrm{A}$. These values are very similar to those found in a group of young healthy adults $(n=15$; nine men, six women) during supine rest [median (range): NA, $1.71 \mathrm{nmol} / \mathrm{L}$ (1.16-2.80); A, $0.47 \mathrm{nmol} / \mathrm{L}(0.27-1.19)](20)$.

\section{DISCUSSION}

Our results show that there is no difference between the CAT concentrations in arterial blood and capillary blood from the hyperemic heel (Fig. 1, Table 1) in newborns. This agrees with recent findings in adults, where we could show that capillary blood from hyperemic earlobe and nonhyperemic fingertip resembles arterial blood in its CAT content (20). Moreover, significant correlations exist between arterial as well as capillary CAT

Table 1. Comparison of arterial vs hyperemic and nonhyperemic capillary plasma CAT

\begin{tabular}{|c|c|c|c|c|}
\hline $\mathrm{CAT}(\mathrm{nmol} / \mathrm{L})$ & \multicolumn{2}{|c|}{$\begin{array}{l}\text { Arterial vs capillary (hyperemic) } \\
\qquad(n=18)\end{array}$} & \multicolumn{2}{|c|}{$\begin{array}{l}\text { Arterial vs capillary (nonhyperemic) } \\
\qquad(n=9)\end{array}$} \\
\hline Median $(\mathrm{pg} / \mathrm{mL})$ & $\begin{array}{c}2.13 \\
(360)\end{array}$ & $\begin{array}{c}2.41 \\
(408)\end{array}$ & $\begin{array}{c}1.78 \\
(301)\end{array}$ & $\begin{array}{c}3.47 \\
(587)\end{array}$ \\
\hline Range $(\mathrm{pg} / \mathrm{mL})$ & $\begin{array}{l}0.61-10.47 \\
(104-1772)\end{array}$ & $\begin{array}{l}1.05-10.23 \\
(178-1731)\end{array}$ & $\begin{array}{l}0.81-12.41 \\
(137-2099)\end{array}$ & $\begin{array}{l}0.84-13.39 \\
(142-2265)\end{array}$ \\
\hline $\begin{array}{l}\text { Wilcoxon test } \\
\text { Pearson product-moment } \\
\text { correlation }\end{array}$ & \multicolumn{2}{|c|}{$\begin{aligned} & \mathrm{NS} \\
r & =0.966^{*} \\
p & <0.05\end{aligned}$} & \multicolumn{2}{|c|}{$\begin{aligned} p & <0.03 \\
r & =0.784 \\
p & <0.05\end{aligned}$} \\
\hline \multicolumn{5}{|l|}{ A } \\
\hline Median $(\mathrm{pg} / \mathrm{mL})$ & $\begin{array}{c}0.75 \\
(137)\end{array}$ & $\begin{array}{c}0.72 \\
(132)\end{array}$ & $\begin{array}{r}0.34 \\
(63)\end{array}$ & $\begin{array}{r}0.38 \\
(70)\end{array}$ \\
\hline Range $(\mathrm{pg} / \mathrm{mL})$ & $\begin{array}{r}0.16-1.70 \\
(29-312)\end{array}$ & $\begin{array}{r}0.10-1.37 \\
(18-252)\end{array}$ & $\begin{array}{r}0.16-0.61 \\
(30-112)\end{array}$ & $\begin{array}{r}0.17-0.75 \\
(32-138)\end{array}$ \\
\hline $\begin{array}{l}\text { Wilcoxon test } \\
\text { Pearson product-moment } \\
\text { correlation }\end{array}$ & \multicolumn{2}{|c|}{$\begin{aligned} & \mathrm{NS} \\
r & =0.894^{*} \\
p & <0.05\end{aligned}$} & \multicolumn{2}{|c|}{$\begin{aligned} & \mathrm{NS} \\
r & =0.754 \\
p & <0.05\end{aligned}$} \\
\hline
\end{tabular}

\footnotetext{
* Arterial $v s$ capillary (hyperemic) without hemolytic samples $(n=2)$ : NA, $r=0.951 ; \mathrm{A}, r=0.929 ; p<0.05 ; n=16$.
} 

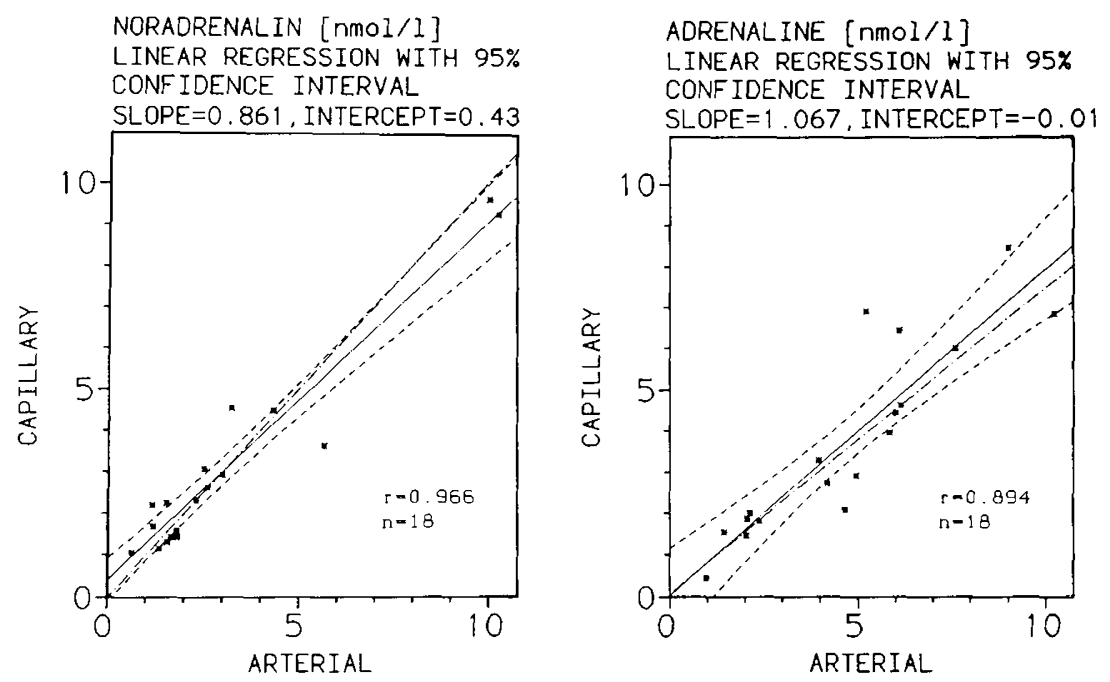

Fig. 1. Comparison of plasma NA and A concentrations of arterialized capillary blood with the respective plasma concentrations of simultaneously collected arterial blood. The fitted regression lines $(-)$ do not differ significantly ( $95 \%$ confidence interval, - - -) from the lines of identity (slope $=1, \cdots \cdot \cdot$.
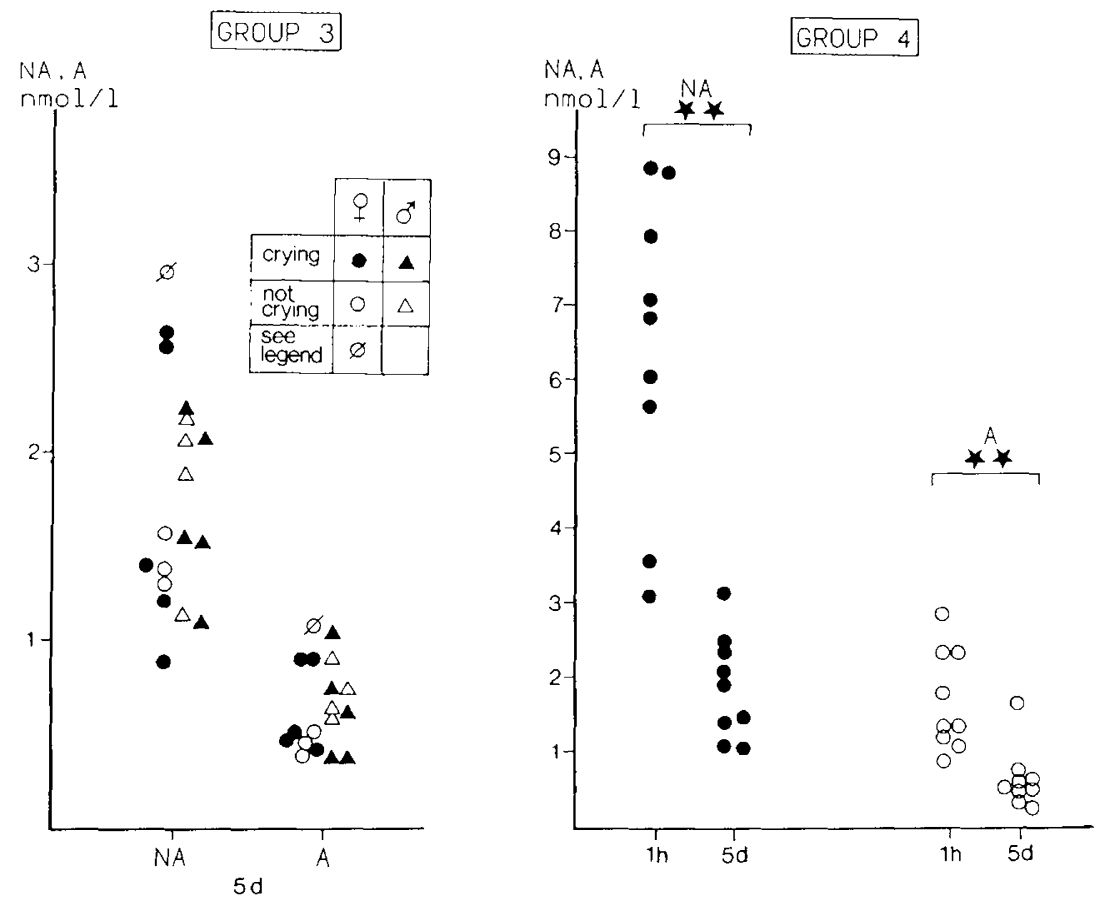

Fig. 2. NA and A concentrations in arterialized capillary plasma of healthy infants. Group 3, Comparison of catecholamine values of 18 infants (nine girls and nine boys) approximately $5 \mathrm{~d}$ after birth $(5 \mathrm{~d})$. There was a significant difference between NA and A levels $(p<0.001)$, but no difference between the sexes or between those infants who cried and those who did not cry during blood sampling ( $\varnothing$; in one case no information was available). Group 4, NA $(\bullet)$ and A $(O)$ concentrations in nine infants are significantly higher at $1 \mathrm{~h}(\mathrm{Ih})$ after birth than approximately $5 \mathrm{~d}(5 d)$ later $(\star \star, p<0.01)$.

and heart rate, $\mathrm{PCO}_{2}, \mathrm{pH}$, weight, and gestational and postpartal age; thus, capillary $\mathrm{A}$ and $\mathrm{NA}$ can be used as a substitute for arterial CAT in newborns. However, in contrast to adults, hyperemization is apparently more critical in infants, at least for NA. Although A values were not affected considerably, NA levels were much higher in nonhyperemic capillary than in arterial blood (Table 1). Therefore, proper arterialization is a necessary precondition for using the capillary CAT technique correctly in infants. This limits the method to stable cardiovascular conditions. Poor peripheral blood flow preventing arterialization, e.g. due to a state of circulatory centralization, will make results unreliable, a restriction that certainly will also apply for the use of arterialized venous blood (6)

The question of how to deal with hemolytic specimens is important because red cells contain catechol-O-methyl-transfer- ase (21). However, it has been shown that hemolysis does not influence CAT determination with a single isotope radioenzymatic method (18) and with an HPLC procedure (22); the disturbance of a double isotope technique (23) might have been due to peculiarities of this particular method (24). In our procedure, both cooling and the presence of plasma calcium $(25,26)$ will inhibit catechol-O-methyl-transferase before its removal by acid precipitation during sample preparation (19). Moreover, based on experience with capillary samples from adults, hemolysis does not inhibit transmethylation in our single isotope procedure: internal standards give yields (mean \pm SEM) of 170 \pm 3.7 and $177 \pm 8.1 \mathrm{cpm} / 5.9 \mathrm{fM}(\mathrm{cpm} / \mathrm{pg})$ for NA and $195 \pm$ 3.9 and $203 \pm 8.0 \mathrm{cpm} / 5.5 \mathrm{fM}(\mathrm{cpm} / \mathrm{pg})$ for $\mathrm{A}$ in nonhemolytic $(n=69)$ and hemolytic $(n=7)$ capillary samples, respectively (Baumgartner $\mathrm{H}$, unpublished observations). Nevertheless, we 
have adopted the precautionary and somewhat arbitrary practice of processing only "slightly" hemolytic samples.

The well-known fall in circulating CAT after delivery $(1,2,5$, $7,8)$ is clearly reflected in the marked difference $(p<0.01)$ between the levels at $1 \mathrm{~h}$ and approximately $5 \mathrm{~d}$ later (Fig. 2; group 4). The values found on approximately $\mathrm{d} 5$ in group 3 and 4 (Fig. 2) are in the same range as those reported previously by others $(1,2,5)$ and very similar to those of resting supine adults, as mentioned in the results. Like others, we found no sex difference in plasma CAT after normal term delivery (4).

The capillary CAT levels [median (range)] of 13 patients from group $1[\mathrm{NA}, 2.12 \mathrm{nmol} / \mathrm{L}(1.05-3.13) ; \mathrm{A}, 0.41 \mathrm{nmol} / \mathrm{L}(0.098-$ 1.25)] at approximately $5 \mathrm{~d}$ after birth were in the range of the healthy babies [NA, $1.58 \mathrm{nmol} / \mathrm{L}(0.89-3.16) ; \mathrm{A}, 0.59 \mathrm{nmol} / \mathrm{L}$ $(0.25-1.64) ; n=27$ ]. Five patients, however, had considerably higher NA [NA, $4.63 \mathrm{nmol} / \mathrm{L}(3.69-10.23)]$ and rather high A values $[1.29 \mathrm{nmol} / \mathrm{L}(0.65-1.37)]$. The latter patients were all preterm infants with lower gestational age (32 versus 36 wk median; $p<0.05)$ and birth weight $(1550$ versus $2550 \mathrm{~g} ; p<$ 0.05 ), but higher heart rates ( 160 versus $141 \mathrm{bpm} ; p<0.01$ ), and capillary NA $(p<0.001)$ and A $(p<0.01)$ levels than the other patients in group 1 . Thus, although some preterm babies did mount a substantial, predominantly noradrenergic, stress response indicating postnatal challenge, sympatho-adrenomedullary activity was not increased in most of these term and preterm intensive care patients. The significant correlations found for group $\mathrm{I}$ between CAT and gestational age, weight, $\mathrm{pH}, \mathrm{PCO}_{2}$, and heart rate rests on the inclusion of the high NA subgroup of preterm babies.

The modalities of blood sampling for CAT analysis may vary considerably during the early stages of life. The enormous CAT surge of "the stress of being born" has been estimated on scalp blood during labor (15) and assessed on umbilical artery blood (1-14). After delivery, arterial or venous blood is the usual source. Both sampling methods, however, have ethical and practical limitations $(1,17)$, particularly in healthy infants and when intended for research purposes exclusively. Parental consent to collect a few drops of capillary blood can easily be obtained under these circumstances, especially when puncture is required for routine medical or public health purposes, as was the case in our healthy infants. Using capillary plasma CAT can thus be a convenient and reliable way to assess sympatho-adrenomedullary activity in infants during perinatal adaptation $(1,2,5,16)$, as well as during later stages of development $(2,17)$.

\section{REFERENCES}

1. Eliot RJ, Lam R, Leake RD, Hobel CJ, Fisher DA 1980 Plasma catecholamine concentrations in infants at birth and during the first 48 hours of life. $J$ Pediatr $96: 311-315$

2. Leonetti G, Bianchini C, Picotti GB, Cesura A, Caccamo L, Marini A 1980
Plasma catecholamines and plasma renin activity at birth and during the first days of life. Clin Sci 59:319s-321s

3. Faxelius G, Lagercrantz H, Yao A 1984 Sympathoadrenal activity and peripheral blood flow after birth: comparison in infants delivered vaginally and by cesarean section. J Pediatr 105: 144-148

4. Padbury JF, Roberman B, Oddie TH, Hobel CJ, Fisher DA 1982 Fetal catecholamine release in response to labor and delivery. Obstet Gynecol 60:607-611

5. Broberger U, Hansson U, Lagercrantz H, Persson B 1984 Sympathoadrenal activity and metabolic adjustment during the first 12 hours after birth in infants of diabetic mothers. Acta Paediatr Scand 73:620-625

6. Hägnevik K, Faxelius G. Irestedt L, Lagercrantz H, Lundell B, Persson B 1984 Catecholamine surge and metabolic adaptation in the newborn after vaginal delivery and cesarean section. Acta Paediatr Scand 73:602-609

7. Hertel J, Christensen NJ, Pederson SA, Kühl C 1982 Plasma noradrenaline and adrenaline in infants of diabetic mothers at birth and two hours of age. Acta Paediatr Scand 71:941-945

8. Hertel J, Kühl C, Christensen NJ, Pederson SA 1985 Plasma noradrenaline and adrenaline in newborn infants of diabetic mothers: relation to plasma lipids. Acta Paediatr Scand 74:521-524

9. Faxelius G, Hägnevik K, Lagercrantz H, Lundell B, Irestedt L 1983 Catecholamine surge and lung function after delivery. Arch Dis Child 58:262-266

10. Lagercrantz H. Bistoletti P 1977 Catecholamine release in the newborn infant at birth. Pediatr Res 11:889-893

11. Nylund L, Dahlin I, Lagercrantz H 1987 Fetal catecholamines and Apgar score. J Perinat Med 15:340-344

12. Greenough A, Lagercrantz H, Pool J, Dahlin I 1987 Plasma catecholamine levels in preterm infants. Acta Paediatr Scand 76:54-59

3. Bader M, Datta S, Arthur R, Benvenutti E, Courtney M, Hauch M 1990 Maternal and fetal catecholamines and uterine incision-to-delivery interval during elective cesarean. Obstet Gynecol 74:600-603

14. Schneider H, Prögler M. Ziegler WH. Huch R 1990 Biochemical changes in the mother and the fetus during the labor and its significance for the management of the second stage. Int J Gynaecol Obstet 31:117-126

15. Bistoletti P, Nylund L, Lagercrantz H, Hjemdahl P, Ström H 1983 Fetal scalp catecholamines during labor. Am J Obstet Gynecol 147:785-788

16. Costa A. De Fillippis V, Voglino M. Giraudi G, Massobri M, Benedetto C. Marozio L, Gallo M, Molina G, Fabris C, Bertino E, Licata D 1988 Adrenocorticotropic hormone and catecholamines in maternal, umbilical and neonatal plasma in relation to vaginal delivery. J Endocrinol Invest 1 1:703-709

17. Planz G, Bieber J, Mencke HJ, Bernuth GV 1983 Plasma catecholamines in children. Experientia 39:871

18. Smith RT 1980 Effect of in vitro hemolysis on assay of plasma catecholamines and DOPA. Clin Chem 26:1354-1356

19. Baumgartner H, Ridl W, Klein G, Preindl S 1983 Improved radioenzymatic assay for determination of catecholamines in plasma. Clin Chim Acta 132:111-116

20. Baumgartner H, Wiedermann CJ, Hörtnagl H, Mühlberger V 1985 Plasma catecholamines in arterial and capillary blood. Naunyn Schmiedebergs Arch Pharmacol 328:461-463

21. Axelrod J, Cohn CK 1971 Methyltransferase enzymes in red blood cells. J Pharmacol Exp Ther 176-650-654

22. Rossi G, Deppieri O, Pessina AC 1986 Effect of hemolysis on high-performance liquid chromatography measurements of free plasma catecholamines. J Chromatogr 380:117-121

23. Causon RC, Murphy MB, Brown MJ 1982 Effect of hemolysis on radioenzymic assay of plasma catecholamines. Clin Chem 28:548-550

24. Smith RT 1982 Effect of hemolysis on radioenzymatic assay of plasma catecholamines. Clin Chem 28.550

25. DeChamplain J, Farley L, Cousineau D, Van Ameringen MR 1976 Circulating catecholamine levels in human and experimental hypertension. Circ Res 38:109-114

26. Weinshilboum RM, Raymond FA 1976 Calcium inhibition of rat liver catechol-O-methyltransferase. Biochem Pharmacol 25:573-579 